\section{Working on the front line: how do you cope?}

\author{
Phil Wiffen
}

In this issue of $E J H P$, we publish a letter from Hospital pharmacists working in Shanghai, China. Xu et $a l^{1}$ describe a situation that is faced by pharmacists on the front line in the outpatient pharmacy of Shanghai Jiaotong University Affiliated Sixth People's Hospital. Patients who for various reasons have become disgruntled with their care use the collection of their outpatient medicines for pharmacy staff as an opportunity to express their frustrations. The letter describes the stresses felt by patients who do not have the outcomes they had hoped for.

Is this a scenario unique to China or is an increasingly common event? Thinking back to my days of being involved in outpatient pharmacy sections, I am struggling to think of occasions where people got upset. Of course there were always the minor issues with ambulance drivers but most patients accepted that their prescriptions particularly for transplant patients would take quite a while to be dispensed. I recall one elderly lady who made sure that she had appointments for the morning and afternoon in different departments so regarded the event as a whole day out and was always ready to chat. I can also recall occasions when the wrong medicine was dispensed requiring a visit to a patients home to rectify the situation but invariably patients were very grateful for the trouble taken.

Correspondence to Professor Phil Wiffen, Pain Research Unit, Churchill Hospital, Old Rd, Oxford OX3 7LE, UK; phil.wiffen@ndcn.ox.ac.uk
Data are hard to find particularly regarding hospital pharmacy, but there is advice and experience from colleagues in community pharmacy who are more likely to experience violence in the form of attempted or actual robbery of cash or controlled substances.

In 2012, 15 per cent of all hospital staff in the UK experienced physical violence from patients in the previous 12 months, with front line emergency staff at a greater risk. ${ }^{2}$

Some hospitals have introduced conflict resolution training but few staff state that they feel more secure after such training.

A US blog from the Centers for Disease Control and Prevention also reports attacks against pharmacies as attempted robbery but responses on the associated blog suggest that the issue may be wider that a theft issue including factors in the physical design of a pharmacy department that reduces security. ${ }^{3}$

If such events as described by the Shanghai staff are becoming more common then that raises a number of issues.

Is conflict resolution and appropriate training a part of the undergraduate curriculum? How do you train staff to cope? How do you help staff who have experienced abuse either verbal or physical?

Do you have any experience to share? What advice would you offer to the pharmacy team in Shanghai?

Sometimes staff are required to work alone, this might apply to weekend working, on-call or as a resident. If your department requires this then what policies, if any, do you have in place? Is it time for action?
The following safety checklist was published in the Pharmaceutical Journal some 6 years ago ${ }^{4}$ :

- Are staff trained in good customer service and conflict resolution?

- Are staff confident? (an atmosphere of fear can increase the likelihood of violence)

- Are staff aware of customers with a history of violence?

- Are security measures up to date? (eg, video cameras or alarm systems, coded security locks on the doors, wider counters)

- Can lone worker situations be avoided?

- Do staff know how to report violence?

There is also advice in this paper on conducting risk assessments.

If you have been affected by this issue or have observations, comments or policies please write to the editor email.

Competing interests None.

Provenance and peer review Commissioned; internally peer reviewed.

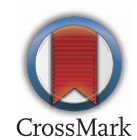

To cite Wiffen P. Eur J Hosp Pharm 2014;21:319.

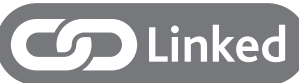

http://dx.doi.org/10.1136/ejhpharm-2014-000548

Eur J Hosp Pharm 2014:21:319.

doi:10.1136/ejhpharm-2014-000559

\section{REFERENCES}

$1 \mathrm{Ma} E$, Fang M, Xu F. Pharmacist dispense under a doctor-patient tension: how should we deal with this? Eur J Hosp Pharm 2014;21:378.

2 Wright C, Price J, Cooper N, et al. Violence in A\&E: the zero tolerance myth. Health Serv $J 7$ May 2014.

3 http://blogs.cdc.gov/niosh-science-blog/2009/02/17/ pharmacists/ (accessed 26 Aug 2014).

4 Jankovic $S$. How to protect the safety of your staff in the workplace. Pharm J 3 Jun 2008. 